\title{
A TEMPORADA DE MINICURSOS COMO FERRAMENTA DE CAPACITAÇÃO PARA UNIVERSITÁRIOS
}

Adriel C. da C. e Silva ${ }^{1}$; Ana Laureline A. de Carvalho ${ }^{1}$; Antonia Guilena de M. Rocha ${ }^{1}$; Antonio Henrique A. Carneiro'; Brenda Arielly M. Rodrigues ${ }^{1}$; Gabriel D. Lima $^{1}$; Gabriela M. de Oliveira ${ }^{1}$; Gustavo B. Rodrigues ${ }^{1}$; Isabele S. Farias ${ }^{1}$; Ivana Maria F. Silva ${ }^{1}$; Jefferson de S. Facó ${ }^{1}$; Joelia S. Cavalcante'; Jonatas M. de F. C. Martins $^{1}$; Larissa M. de Freitas ${ }^{1}$; Letícia de Fátima S. Brasil ${ }^{1}$; Lucas F. Firmeza ${ }^{1}$;

Pedro Ygor R. Mesquita ${ }^{1}$; Renata M. Jovino'; Alexandre A. Bertini².

${ }^{1}$ Estudante do curso de Engenharia Civil da Universidade Federal do Ceará

2 Tutor do PET Engenharia Civil e Professor do Departamento de Engenharia Estrutural e Construção Civil da Universidade Federal do Ceará

PET Engenharia Civil, Universidade Federal do Ceará, Fortaleza, Ceará.

Palavras-chave: Mercado de Trabalho; Desenvolvimento; Atualização.

\section{Introdução}

Com o passar do tempo, o ser humano tem sido beneficiado cada vez mais por meio do avanço de técnicas antigas, na criação de novas técnicas e pela aparição de mecanismos que facilitem ações que, anteriormente, poderiam ter uma execução mais demorada. Algumas destas novidades podem ser evidenciadas no avanço das tecnologias computacionais, por meio da criação de softwares que auxiliem o seu usuário em uma determinada função.

A construção civil, como outras áreas, se aproveitou destes avanços e os incorporou em seus serviços. É fácil encontrar, nos dias de hoje, softwares que realizem trabalhos que, tempos atrás, eram realizados à mão, como o Autodesk Revit, no qual o usuário pode modelar uma edificação em 3 dimensões (3D) em poucas horas, trabalho que duraria meses, algumas décadas atrás.

Contudo nas universidades brasileiras ainda há certo atraso no que tange à adesão destes novos modelos de gestão, computacionais e etc. De acordo com Ana Elena 
Schalk, doutora em ciências da educação pela Universidade de Sevilha, o formato adotado pelo ensino superior brasileiro é similar ao abordado no século 18, com uma estrutura ultrapassada que não tem preparado os universitários para as novas profissões nem atualizado as já existentes (DE SOUZA; CAPPI, 2017). Vendo por este ponto, é possível notar que várias universidades no Brasil ainda não incluíram em sua estrutura curricular o uso dos softwares mais atuais no mercado de trabalho, como o TQS, e nem o uso de modelos de gestão, como a filosofia Lean Construction. Além disso, as universidades que têm estes conteúdos inclusos em sua estrutura curricular, normalmente, não oferecem uma capacitação para que seus alunos possam aprender, tendo esses que procurar meios externos para que possam obter o conhecimento necessário, precisando, muitas vezes, pagar por isso. Segundo o Manual de Orientações Básicas (MOB) do Programa de Educação Tutorial (PET), as atividades extracurriculares que compõem o Programa visam garantir que os graduandos vivenciem experiências que não estão presentes em estruturas curriculares convencionais, tendo como foco sua formação global, com intuito de os tanto integrá-los ao mercado de trabalho quanto de incentivar o desenvolvimento de estudos em programas de pós-graduação (SUPERIOR, 2006, p. 4). Baseado nisso, o PET do curso de Engenharia Civil da Universidade Federal do Ceará (UFC) elaborou uma atividade, denominada Temporada de Minicursos (TMC). A Temporada de Minicursos é dividida em dois momentos: A TMC Externa e a Interna. A TMC Externa, que acontece no primeiro semestre do ano, tem como intuito ofertar minicursos voltados para as áreas da Engenharia Civil, tendo como facilitadores os próprios PETianos, sendo o público alvo, normalmente, graduandos do curso de Engenharia Civil da UFC. Já a TMC Interna, que ocorre durante o segundo semestre, visa capacitar os integrantes do grupo PET por meio de minicursos de temas variados ofertados por facilitadores convidados ou por PETianos mais experientes que tenham um conhecimento adequado acerca da temática escolhida. A atividade, no geral, objetiva democratizar e disseminar conhecimentos e competências essenciais para um Engenheiro Civil, os quais os graduandos e os PETianos não aprendem no curso de Engenharia Civil, tudo isso visando tornar estes estudantes mais qualificados para, futuramente, ingressar no mercado de trabalho.

\section{Metodologia}


Inicialmente, para as duas modalidades, são elencados alguns PETianos para a coordenar a atividade, no que diz respeito à questão burocrática da mesma, os quais ficam responsáveis por reservar salas, montar cronogramas, entrar em contato com facilitadores, agendar horários e etc.

Para a realização da TMC Externa, o grupo deve, a princípio, definir quais serão os minicursos ofertados, e, para isso, são escolhidos os principais softwares utilizados tanto na graduação quanto no mercado de trabalho e temas que são essenciais para a formação de um Engenheiro Civil. Assim, após a definição dos conteúdos que serão abordados, os PETianos escolhem quais minicursos irão ministrar, de forma que cada minicurso tenha uma dupla responsável. Incentiva-se que todos os membros do grupo PET ministrem pelo menos um dos minicursos.

Feito isso, os coordenadores elencados definem o planejamento da atividade, o qual consiste em elaborar um cronograma que dure cerca de duas a três semanas, com os dias e horários em que irão ocorrer cada minicurso. Procura-se sempre pensar na compatibilidade dos horários dos minicursos com a disponibilidade dos alunos que mais se interessarão por determinado tema, e isso é feito por uma breve análise dos horários das disciplinas ofertadas no semestre. Geralmente, realiza-se a atividade durante os horários de almoço, visto que a probabilidade de ter choques de horário é menor do que em algum turno.

Ademais, fica a cargo de cada dupla definir a carga horária, a ementa, a quantidade de participantes e a forma de ministrar o minicurso. Geralmente, os minicursos são realizados por meio de aulas expositivas e introdutórias acerca do tema, com o auxílio de slides e de softwares. Ao final de cada aula, passa-se uma lista de presença para que se verifique a frequência dos participantes. Exige-se uma frequência de, pelo menos, $75 \%$ para que o participante tenha direito ao certificado.

As inscrições são realizadas através de um formulário online que é divulgado nas redes sociais do PET e dos PETianos. Para confirmar a inscrição, o participante deve entregar $1 \mathrm{~kg}$ de alimento não perecível por minicurso em que está inscrito. Os alimentos arrecadados são doados para instituições de caridade.

Após a realização da atividade, é disponibilizado para os participantes os slides e os outros materiais que tenham sido utilizados pelos facilitadores e realiza-se uma pesquisa de satisfação com os participantes, a fim de avaliar o desempenho dos minicursos, dos materiais disponibilizados, dos facilitadores, da divulgação e da 


\section{VII CONPET}

organização da atividade. Por fim, após averiguar a frequência dos participantes, confeccionam-se os certificados, que são divulgados nas redes sociais do PET.

Já na TMC Interna, inicialmente, os coordenadores da atividade ficam responsáveis por levantar temas relevantes e que sejam interessantes para o grupo. Dessa forma, durante as reuniões semanais, os PETianos elencam os principais temas que poderiam ser abordados nos minicursos internos. Geralmente, escolhem-se temas que visem a capacitação dos PETianos para a carreira profissional e para a realização da parte externa da atividade, buscando sempre temas relevantes na formação completa de um Engenheiro Civil.

Partindo desses temas, contatam-se profissionais, professores, PETianos egressos ou outros grupos PET que tenham maior afinidade com o tema e convidam-os para realizar o minicurso para o grupo. Feito isso, os coordenadores auxiliam os facilitadores com os materiais e o com o local para a realização da atividade.

Após a realização dos minicursos, realiza-se uma pesquisa com os PETianos participantes, a fim de avaliar a organização, o desempenho do facilitador, a qualidade do minicurso e dos materiais disponibilizados, visando sempre melhorar a atividade. Por fim, confeccionam-se certificados para os participantes e para os facilitadores.

\section{Resultados e discussão}

Tendo como base sua sétima edição, realizada no ano de 2018, a TMC Externa contou com 8 minicursos, sendo estes: AutoCAD, Currículo, Excel, Lean Construction, MS Project, Oratória, Revit e Word, com 186 graduandos inscritos, com 147 confirmações em minicursos e com 96 certificados gerados, levando em consideração a necessidade de ter $75 \%$ de presença para obter o certificado. É interessante pontuar que, em sua sétima edição, houve uma inovação na atividade, com a liberação da atividade para outros cursos de graduação e para outras universidades, tendo a adesão de graduandos de 25 cursos diferentes, de 8 universidades distintas.

Com a realização da atividade, foi proposto a alguns participantes uma pesquisa de satisfação contendo algumas perguntas sobre a realização da atividade, podendo-se evidenciar a seguinte resposta: 
Figura 1: "Qual a relevância do conteúdo proposto?"

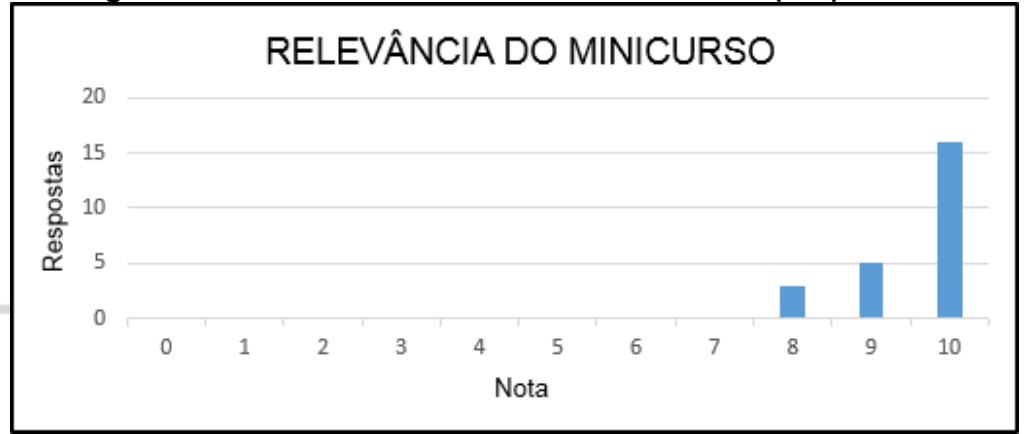

Fonte: Elaborado pelo autor.

Além disso, foi disponibilizado um campo para que os participantes pudessem explicitar pontos positivos e negativos sobre a atividade. Alguns comentários positivos foram elogios a didática dos PETianos, facilitando o entendimento do conteúdo. Já os comentários construtivos questionam a duração do minicurso, incentivando um aumento da carga horária dos minicursos que, em sua maioria, tinham 4 horas de duração.

Ao decorrer da atividade, notou-se que uma das maiores limitações foi a infraestrutura da universidade, que não possibilitava uma grande oferta de vagas, principalmente nos minicursos de software, no qual havia a necessidade de utilizar os laboratórios da universidade. Além disso, percebe-se uma evasão considerável dos participantes, caindo de 147 inscrições confirmadas para 96 certificados gerados. Deduz-se que esta evasão seja decorrente do horário da realização da atividade, que, neste caso, ocorreu durante o horário de almoço (12h à 14h), impossibilitando alguns participantes de comparecerem aos minicursos.

Já a TMC Interna, no segundo semestre de 2018, contou com dois minicursos, sendo estes de Projeto Hidráulico e de Primeiros Socorros. O minicurso de Primeiros Socorros foi ministrado pelo PET Enfermagem da Universidade Estadual do Ceará (UECE). É importante ressaltar que o minicurso de Primeiros Socorros trouxe duas inovações para a atividade do ano de 2018, visto que a atividade só contava com temáticas voltadas para a Engenharia Civil e que nunca teve PETianos de outros cursos como facilitadores. O grupo optou por este minicurso devido a relevância do seu conteúdo para a formação de um profissional e devido a interação gerada entre os grupos PET, criando vínculos mais fortes dentro do movimento InterPET do Ceará e tornando possível criar parcerias para a realização de outras atividades.

Os participantes da atividade, quando questionados sobre a relevância da TMC para seu crescimento profissional, apresentaram os seguintes resultados: 
Figura 2: "Qual sua opinião sobre a relevância da atividade para sua profissão?"

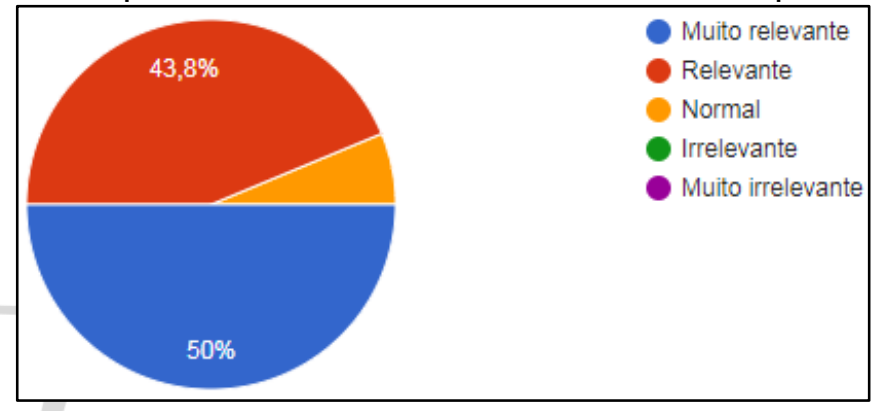

Fonte: Elaborado pelo autor.

\section{Conclusões}

A partir dos resultados, pode-se afirmar que os objetivos da atividade foram atingidos, uma vez que houve a capacitação dos participantes nos temas propostos. Na parte externa da atividade, os PETianos puderam impactar também na formação de alunos de diversos cursos e universidades, além de se aprofundarem em um dos temas ofertados. Com isso, almeja-se que na TMC externa se consiga atrair ainda mais graduandos, por meio da possibilidade de maior contato com os temas abordados, com o aumento da carga horária, e da oferta dos minicursos em melhores horários.

Já na parte Interna, os PETianos puderam aprender com uma PETiana egressa, de forma prática e aplicada, a realizar Projetos Hidráulicos, podendo, então, ofertar esta temática como minicurso externo em edições futuras, cumprindo com um dos objetivos da atividade que é capacitar internamente o grupo para que eles possam impactar a graduação. Por fim, vale enfatizar, também, o impacto positivo da realização do minicurso de Primeiros Socorros, uma vez que além de receber muitos elogios e ser considerada, em sua maioria, relevante, incentivou a possibilidade da atuação de outros grupos PET como facilitadores das próximas edições da atividade.

\section{Referências}

DE SOUZA, T.; CAPPI, L. G. Bacharéis obsoletos em 10 anos. Eu, Estudante, 2017. Disponível em: <https://www.correiobraziliense.com.br/app/noticia/euestudante/tf_carreira/2017/06/04/tf_carreira_interna,600064/bachareis-obsoletos-em10-anos.shtml>. Acesso em: 07 jan. 2019.

SUPERIOR, S. D. E. Manual de Orientações Básicas - PET. Portal do Ministério da Educação, 2006. Disponível em: <http://portal.mec.gov.br/pet/manual-deorientacoes>. Acesso em: 07 jan. 2019. 